\title{
Effectiveness of psychosocial treatment on emotion regulation in people with posttraumatic stress disorder after burn injuries
}

\author{
Y. Aazami ${ }^{1}$ F. Sohrabi $^{1}$, A. Borjali ${ }^{1}$, NA. Farrokhi ${ }^{2}$, S. Farokh Forghani $^{3}$
}

\footnotetext{
${ }^{1}$ Department of Clinical Psychology, Faculty of Psychology and Educational Sciences, Allameh Tabataba'i University, Tehran, Iran

${ }^{2}$ Department of Psychometrics, Faculty of Psychology and Educational Sciences, Allameh Tabataba'i University, Tehran, Iran

${ }^{3}$ Department of Plastic and Plastic Surgery, Burn Research Center, Hazrat Fatemeh Hospital, Iran University of Medical Sciences, Tehran, Iran

Corresponding Address: Faramarz Sohrabi, Department of Clinical Psychology, Faculty of Psychology and Educational Sciences, Allameh Tabataba'i University, Olympic Village, Hemmat West Highway, Tehran.

Tel: +98-21-48393165; Email: Sohrabi@atu.ac.ir

Received: 23 Jun 2018; Accepted: 14 Aug 2018
}

\section{Abstract}

Background: Burn is one of the traumatic events that causes posttraumatic stress disorder (PTSD). The burn survivors often experience major psychological problems.

Objective: This study evaluated the effectiveness of psychosocial model-based treatment plan on emotion regulation strategies in people with PTSD after burn injury.

Methods: The research method was semi experimental with pretest-posttest design with control group. All patients referring to Tehran Shahid Motahari Burn Rescue Hospital participated by using simple random sampling method in 2017. Thirty patients with PTSD diagnosis were selected to the experimental and control groups. The treatment program was conducted during 12 sessions and followed up after two months in the experimental group. The tools of study included a structured diagnostic interview based on the 5th edition of diagnostic and statistical guide (DSM-5), PTSD index (PCL-5) and emotion regulation questionnaire (ERQ). The results were analyzed by multivariate analysis of covariance and $t$ correlation.

Findings: The results showed that the treatment program increased the re-evaluation component (as a positive emotion regulation strategy) and decreased repression scores (as a negative strategy) in PTSD patients due to burn injuries and this effect has been lasting for two months.

Conclusion: Based on the results, it can be concluded that psychosocial therapeutic program is an effective program for PTSD patients and can affect their emotion regulation strategies.

Keywords: Posttraumatic stress disorder, Emotions, Psychosocial factors, Burns, Clinical psychology Citation: Aazami Y, Sohrabi F, Borjali A, Farrokhi NA, Farokh Forghani S. Effectiveness of psychosocial treatment on emotion regulation in people with posttraumatic stress disorder after burn injuries. J Qazvin Univ Med Sci 2018; 22(4): 51-62. 


\title{
تأثير برنامه درمانى روانى - اجتماعى بر راهبردهاى تنظيم هيجان در افراد مبتلا به اختلال

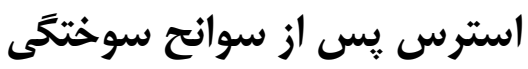

\author{
يوسف اعظمى'، دكتر فرامرز سهر ابي'، دكتر احمد برجعلى'، دكتر نورعلى فرخى'، دكتر سيامك فرخ فرقانى'
}

' كروه روانشناسى بالينى دانشكده روانشناسى و علوم تربيتى دانشكاه علامه طباطبائى، تهران، ايران

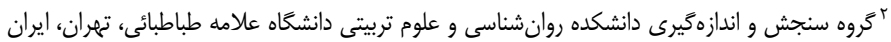

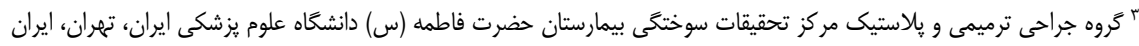

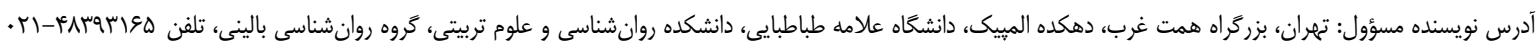

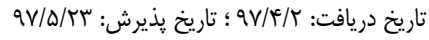

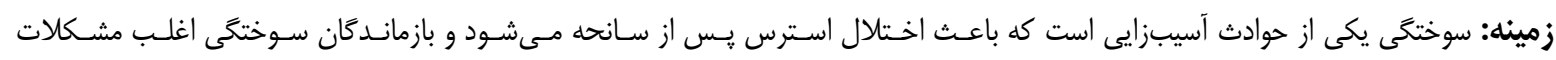

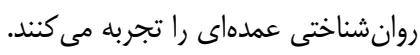

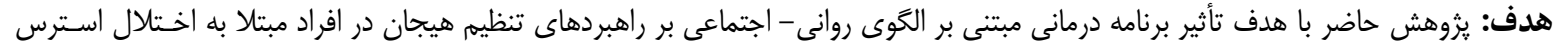

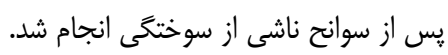

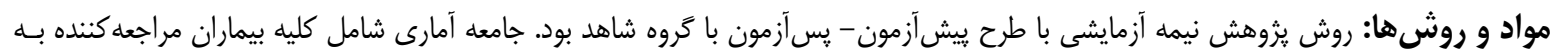

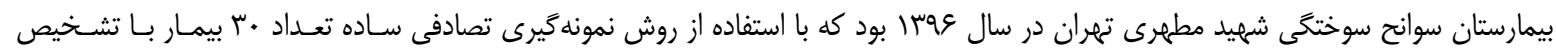

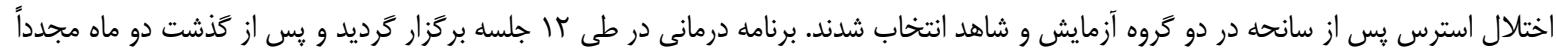

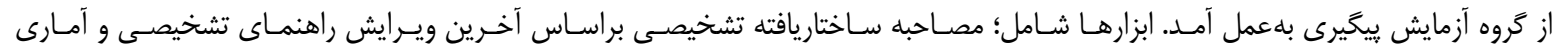

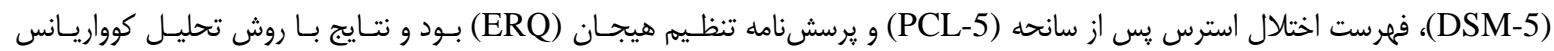

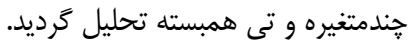

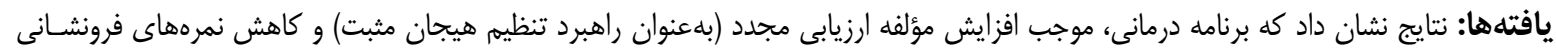

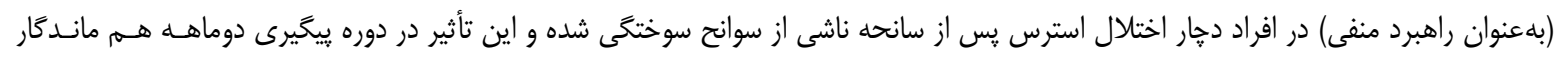
نتيجه كَيرى: براساس نتايج مىتوان كفت برنامه درمانى مبتنى بر الكوى روانى - اجتماعى مناسب و براى بيماران كارآمد است و مىتواند بر تنظيم هيجان هاى آنها مؤثر باشد.

كليدوازهها: اختلال استرس پِ از سانحه، هيجان، عوامل روانى - اجتماعى، سوختخى، روانشناسى بالينى

را از دست مى دهند و بيش از ه9 درصد مـرك و ميرهـاى

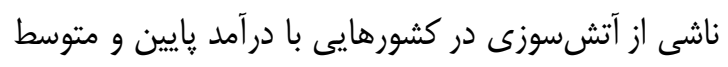

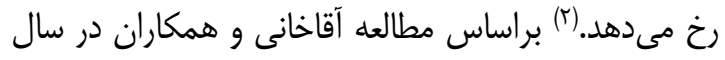

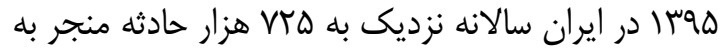

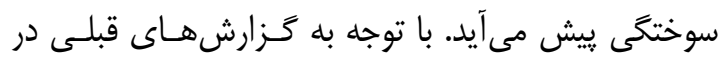

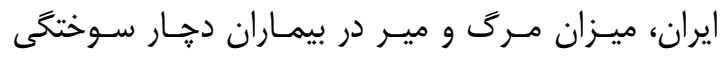

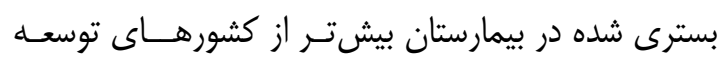

مقدمه:

سوختخى يكى از شايعترين صدمههايى است كـه در

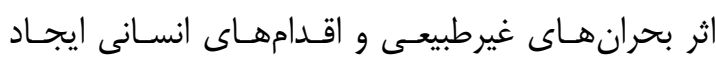

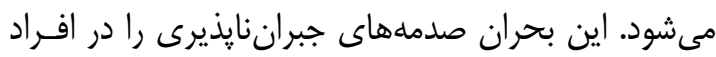

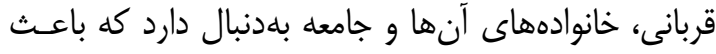
ناتوانى و مرى و وداراى تبعات اقتصادى و اجتماعى شانى شـانديد

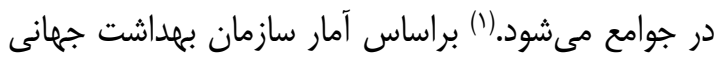

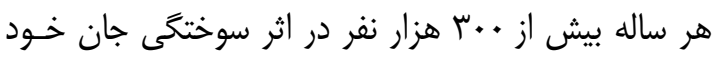


به اختلالهاى وابسته به رويداد آسيبزاو اختلال استرس يس از سانحه اغلب مشكلاتى در تنظيم هيجان دارند.

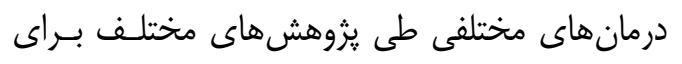

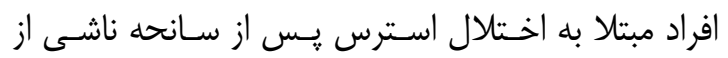
سوانح و آسيبهاى عمدى و غيرعمدى مختلف از قبيـل؛

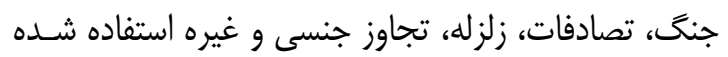

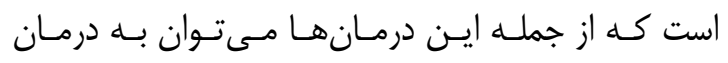

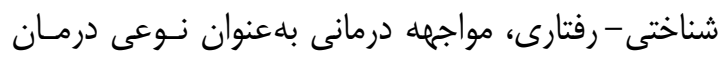

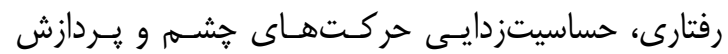

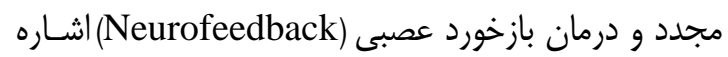

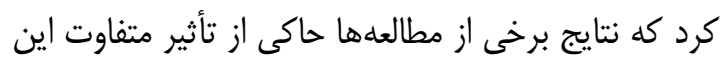

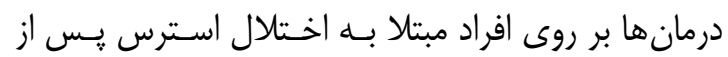

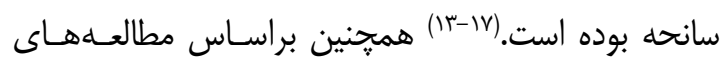

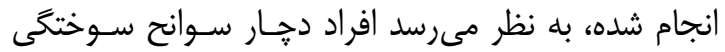

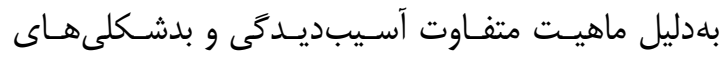

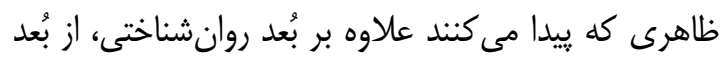
اجتماعى هم دجار آسيب مى شوند و بلنظر نمىرسد صرف

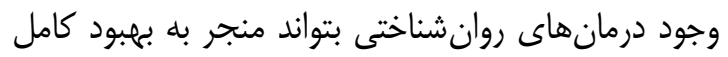

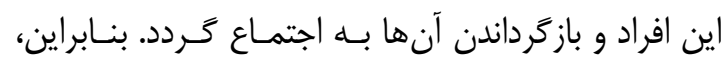

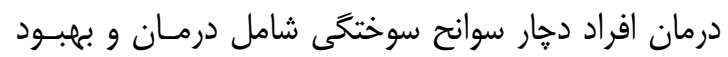

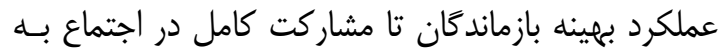

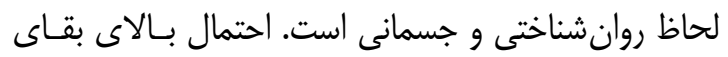

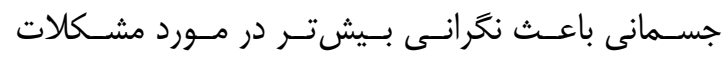

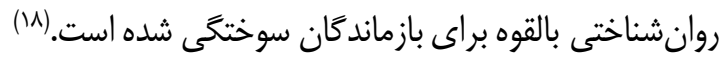

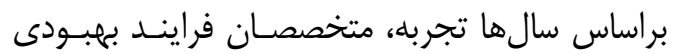

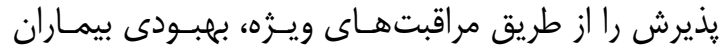

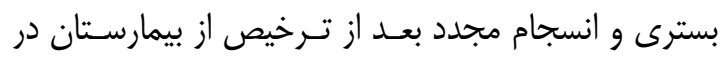

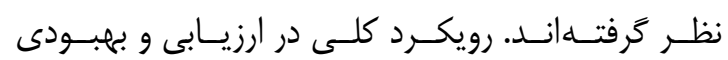

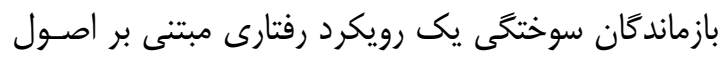
يادَّيرى مانند؛ شرطى سازى عامـل، بازسـازى شــاختى و و

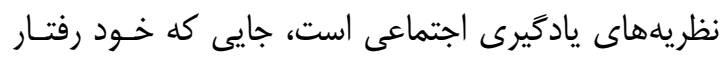

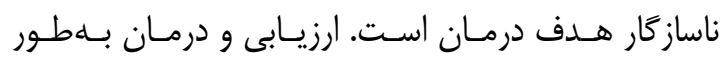

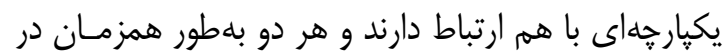

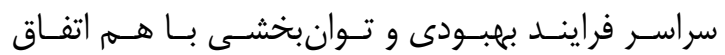

يافته است.(r) ()

جنانجه قربانى سوختخى زنده بماند، خالش جسـمى و

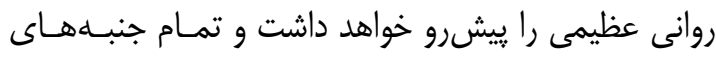

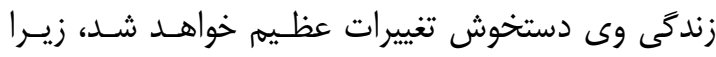

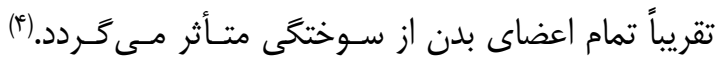

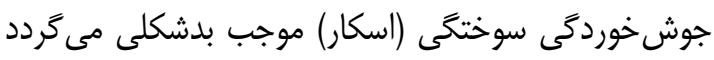

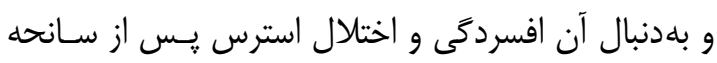
(Post traumatic stress disorder; PTSD) بيماران شـايع بـوده و مشـكلات؛ تصـوير ذهنس، فقـدان اعتماد به نفس، احساس خجالت و كَوشهَيرى نيـز قابـل

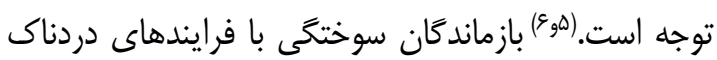

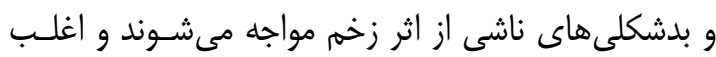

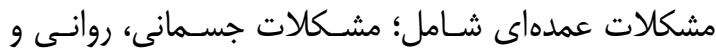

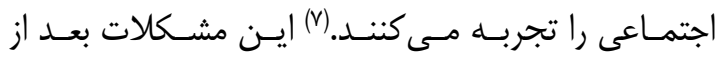

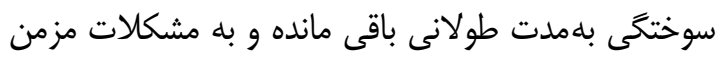

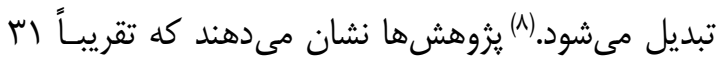

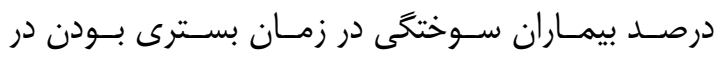

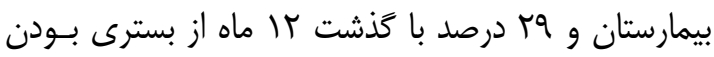

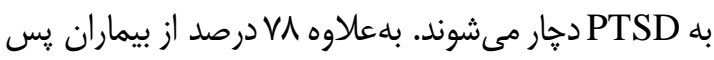

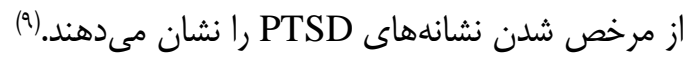
يكى از مشكلاتى كـهـ افـراد دهـار

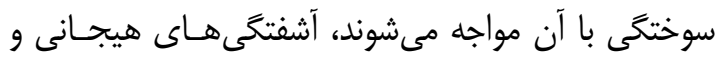

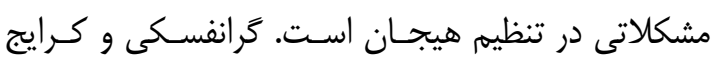

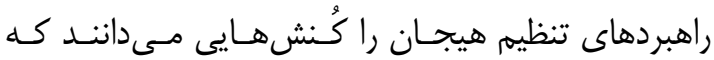

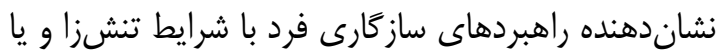

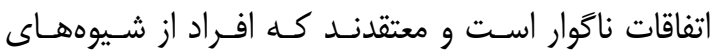

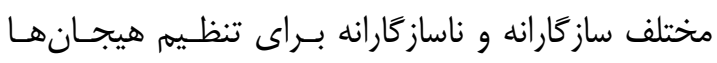

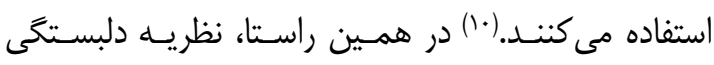
مطرح مى كند كه روشى را كه فرد در موقعيتهاى تنشزاز

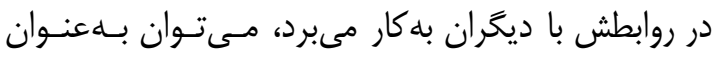

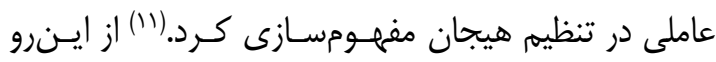

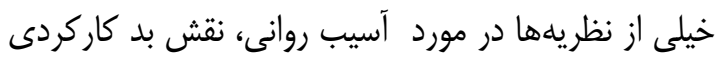

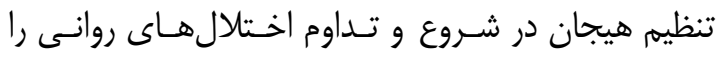

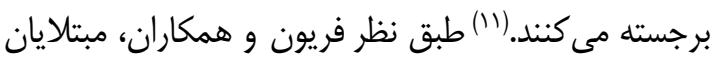


دجار سوختخى مراجعل كننده به بيمارستان شهيد مطهـرى

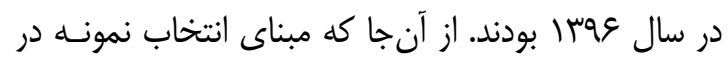

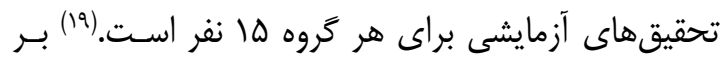

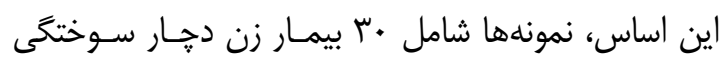

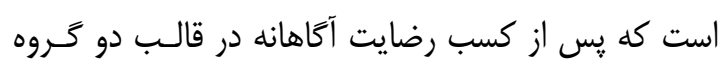

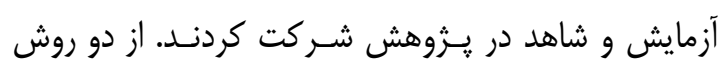

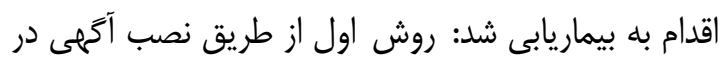

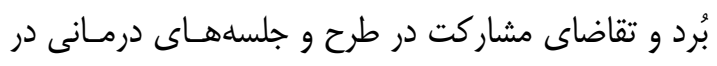

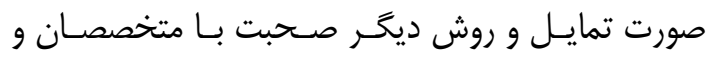

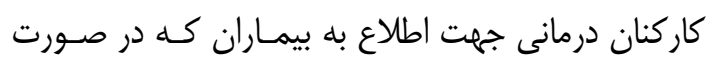

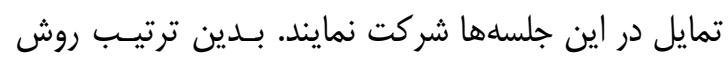

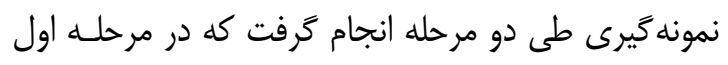

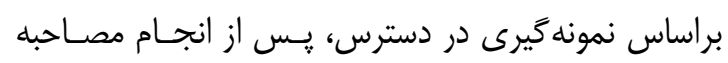

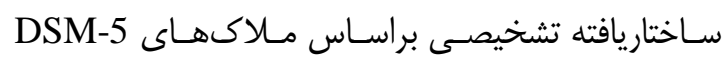

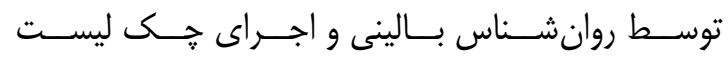

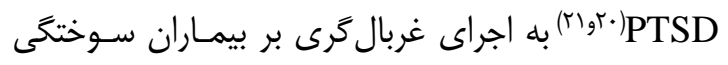

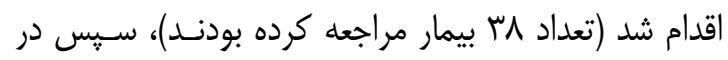

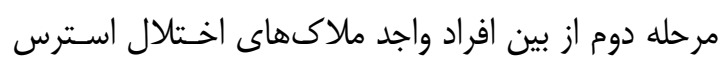

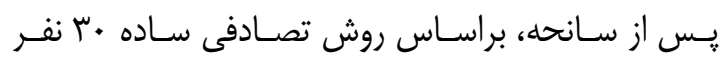

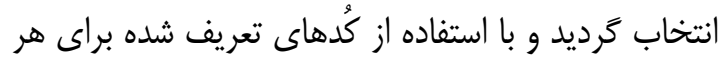

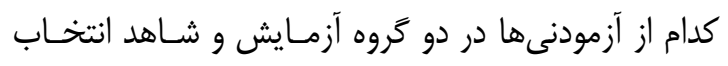

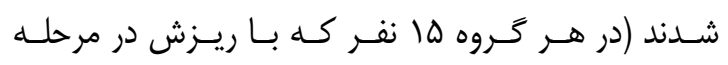

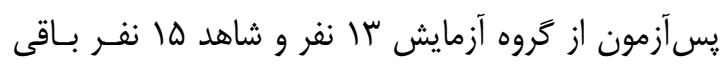

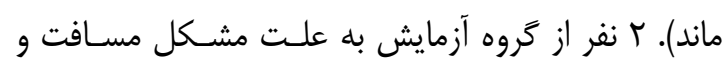

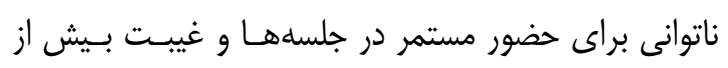
سه جلسه ريزش نمودند.

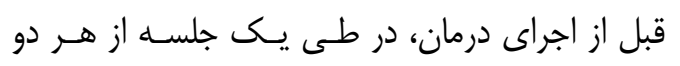

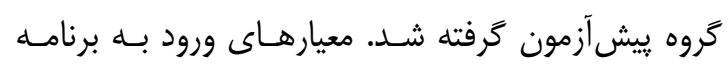

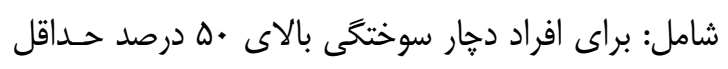

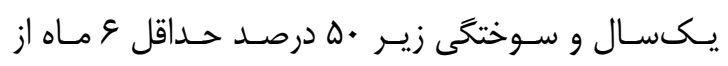

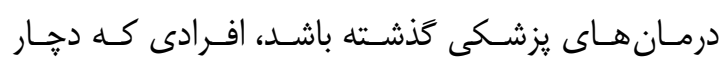

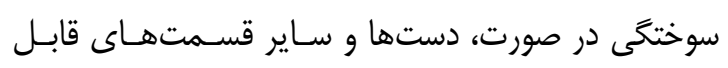

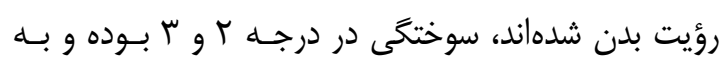

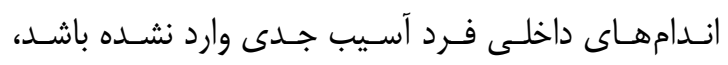

مى افتند.(1) از سوى ديكَر، براسـاس مطالهـهــاى انجـام

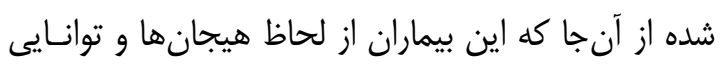

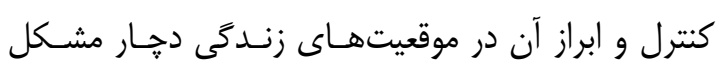

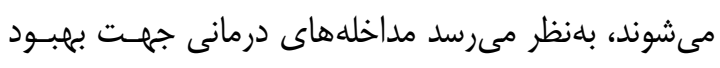

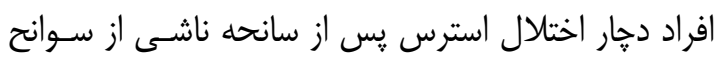

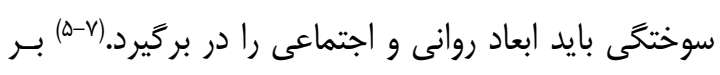

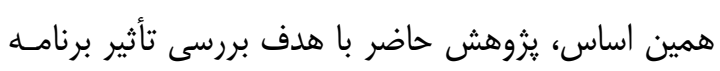

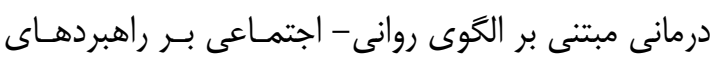

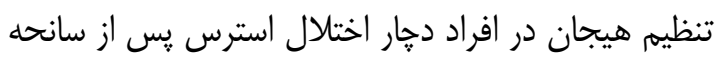
ناشى از سوانح سوختخى انجام شد.

\section{مواد و روشها:}

يزوهش حاضر از نوع يزوهشها:

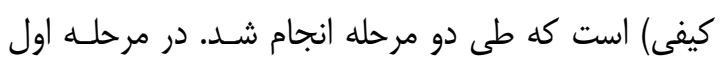

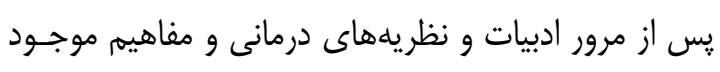

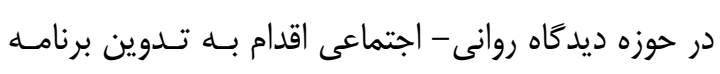

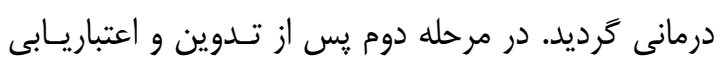

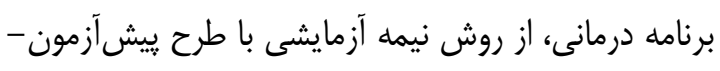

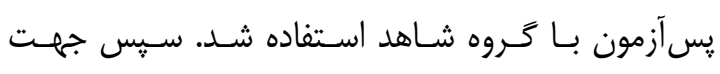

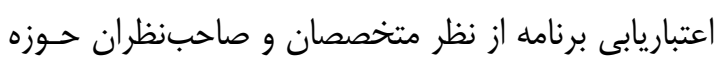

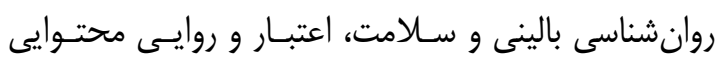

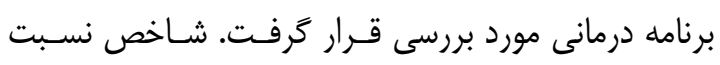

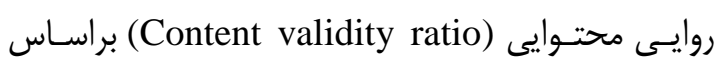

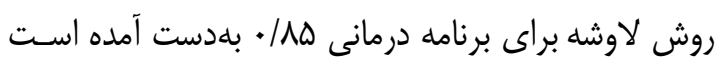

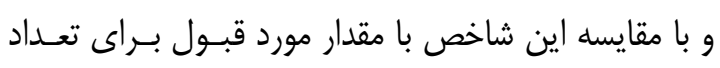

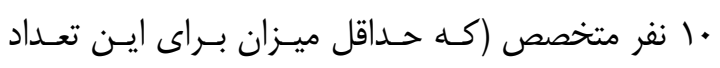

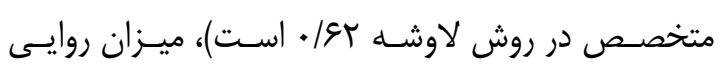

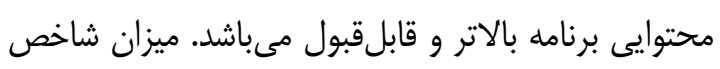

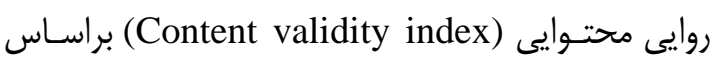

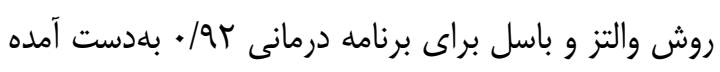

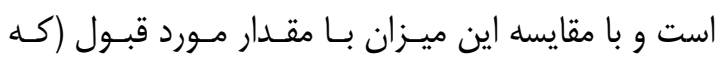

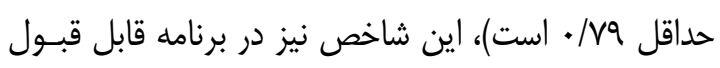
مىباشد. جامعه آمارى يزوهش حاضـر شامـل تمامسى بيمـاران 
يك مقياس خود كزارشدهى است كه براى ارزيابى ميزان

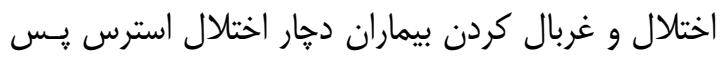

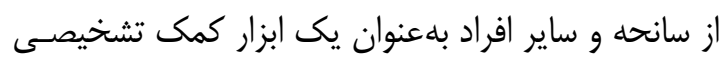

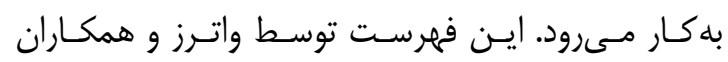

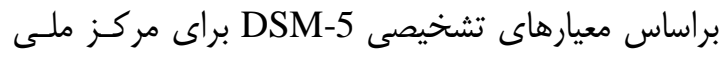

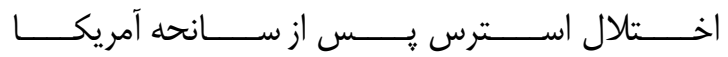
تهييه شد (American National Center for PTSD)

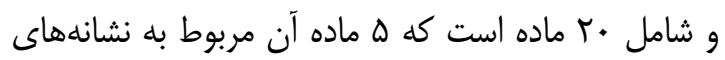

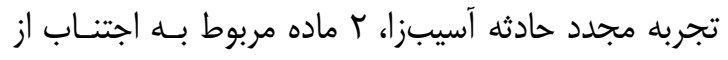
محركهاى مرتبط با رويداد آسيبزا، V ماده آن مربوط بـ ماده مرنه

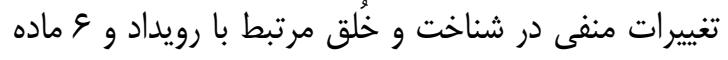

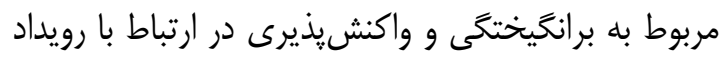

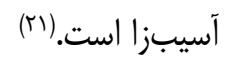

روش نمرهكذارى شامل؛ جمع نمرهها از دامنـه نمـره

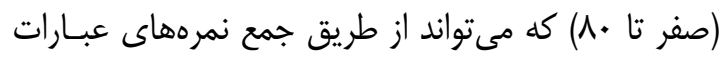

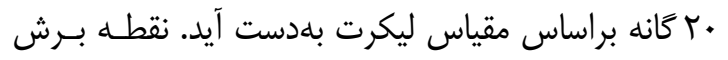

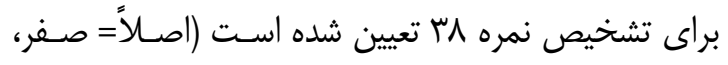

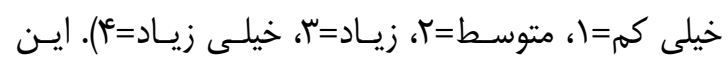

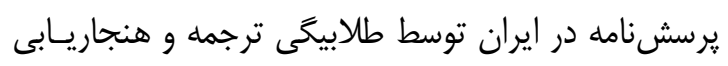

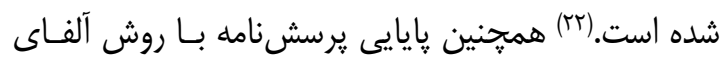

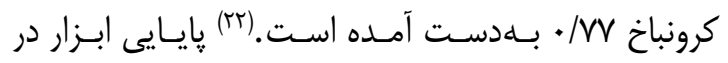

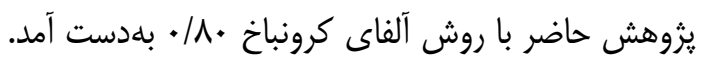

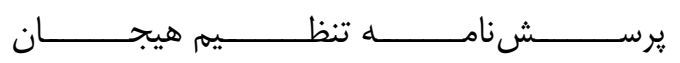

يك مقيـاس هيجان (Emotion regulation questionnaire)

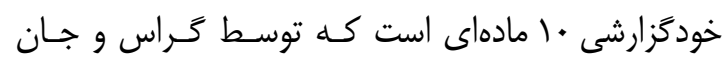

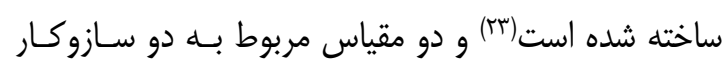

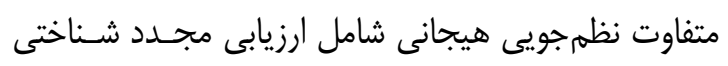

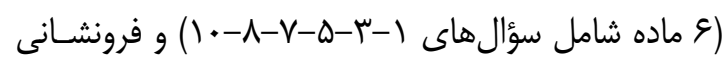

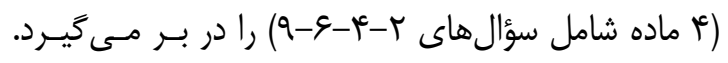

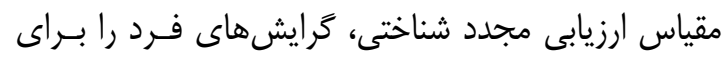

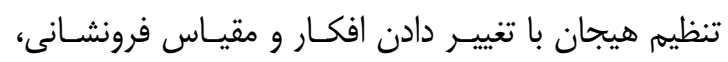

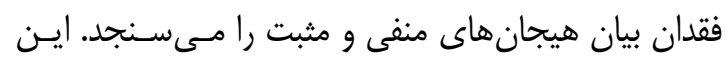

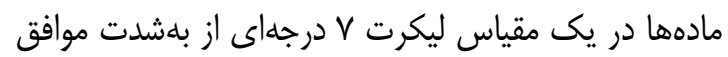

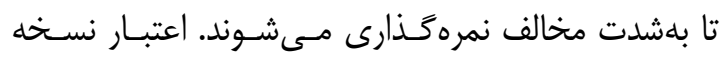

سوختخى در اثر حوادث اتفاقى و غيرعمـــ رخ داده باشـد، واجد ملاكهاى PTSD براسـاس مصـاحبه سـاختاريافته

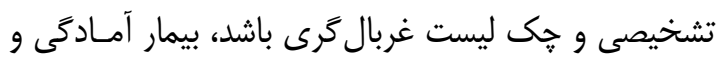

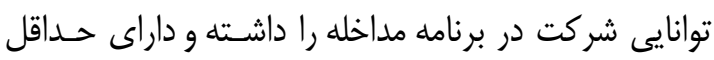

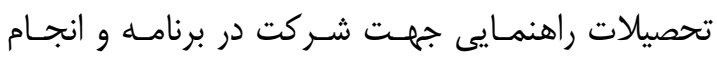

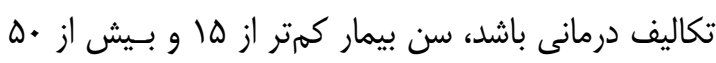

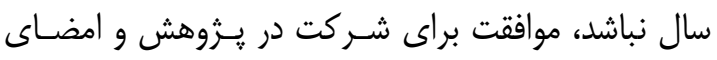
رضايتنامه كتبى. سابقه مصرف داروهاى مخدر و الكل، نـاتوانى جهـت

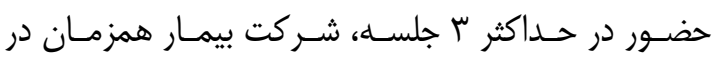

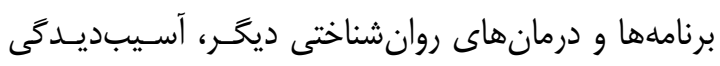

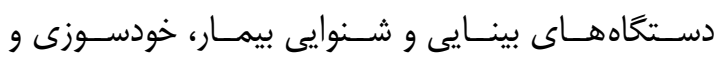

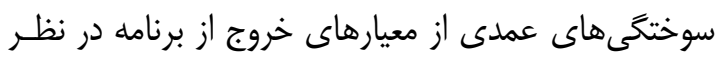

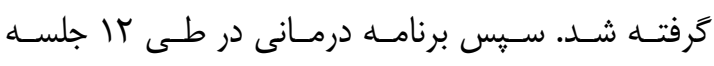

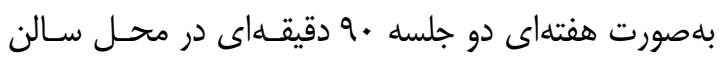

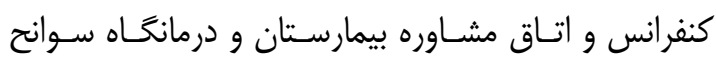
سوختخى شهيد مطهرى تهران بلمدات يك ماه و ونسيهم بــر

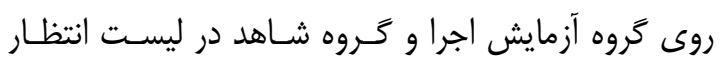

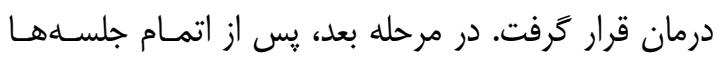

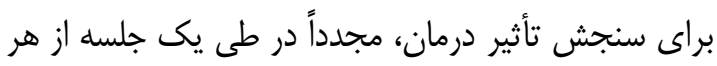

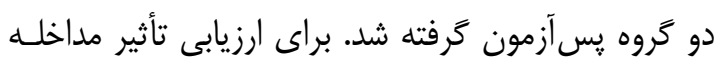

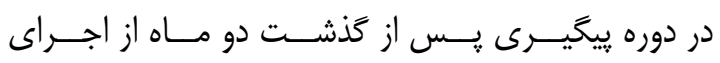

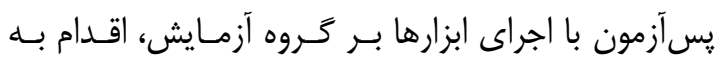

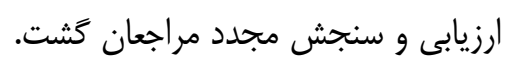

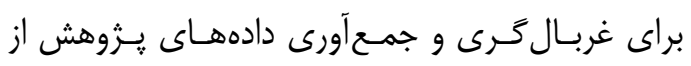
ابزارهاى زير استفاده كرديد:

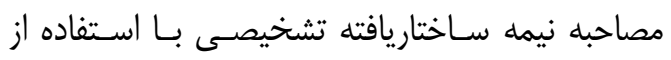

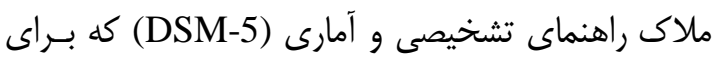

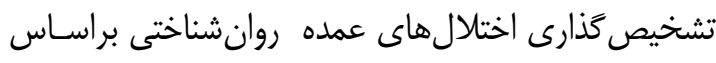

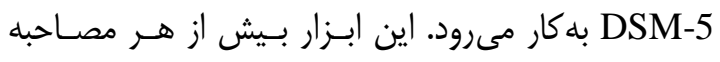

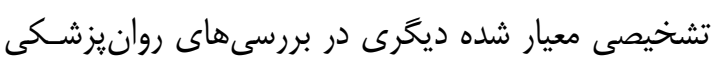

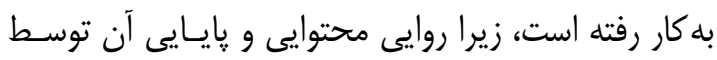

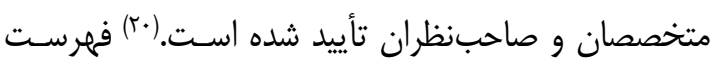
اختلال استرس يـس از سـانحه (5TSD checklist 
به اصلاح محتواى برنامه درمانـى اقــام نماينـــ. خلاصـه جلسههاى درمانى در جدول شماره آمآمده است.

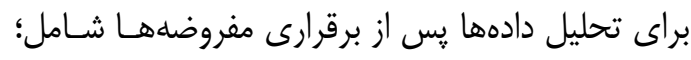

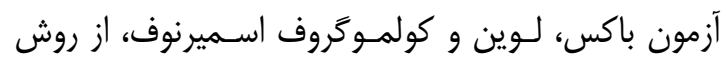

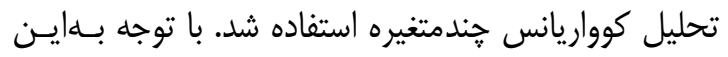

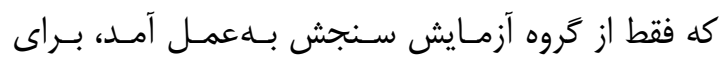

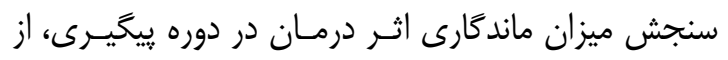

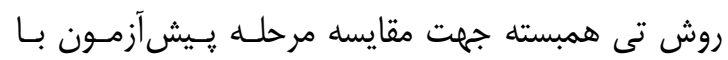
يبيخيرى استفاده شد.

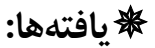

اطلاعات جمعيتشناختى افراد مورد مطالعه در جدول r آمده است. همجنين در گروه شاهد بيشترين سوختكى إنى

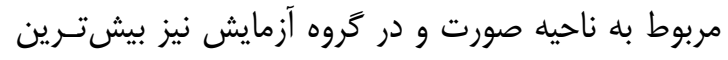
سوختخى مربوط به نواحى گردن و اندام فوقانى است.
فارسى يرسشنامه با استفاده از بازآزمايى و تحليل عامـل،

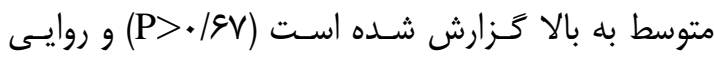

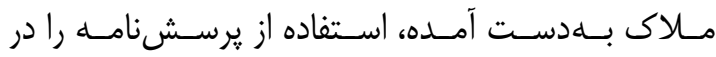

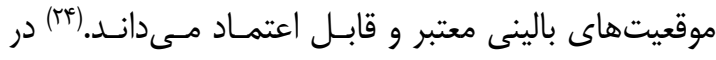

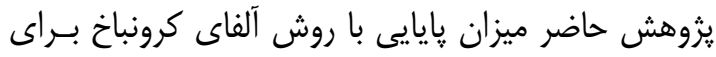

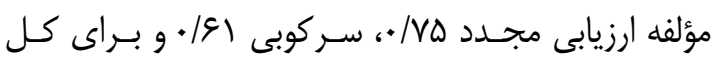
مقياس V9/ • بلهدست آمد.

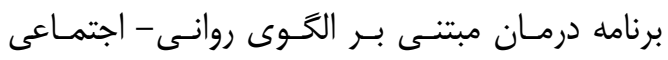

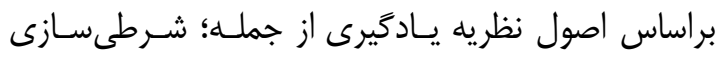

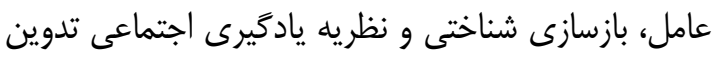

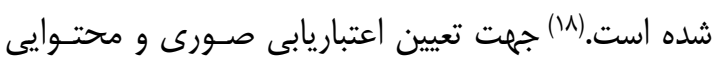

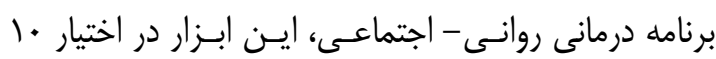

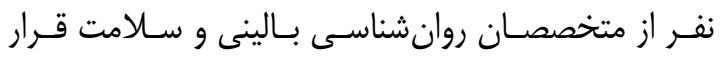

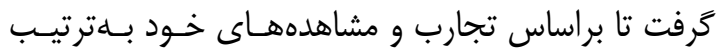

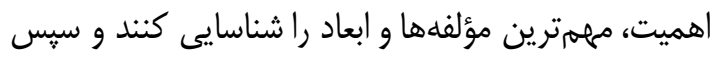

\section{جدول ( - خلاصه جلسههاى برنامه درمانى مبتنى بر الكَى روانى - اجتماعى}

\begin{tabular}{|c|c|c|}
\hline 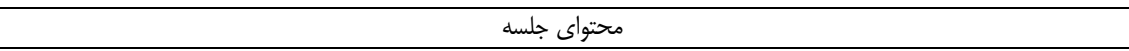 & 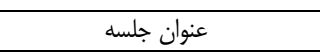 & جلسه \\
\hline 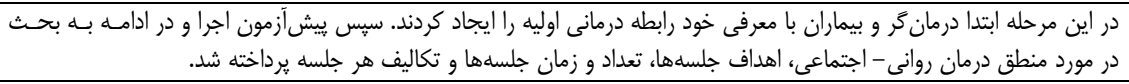 & معرفى، اجراى بيشآزمون و بيان & اول \\
\hline 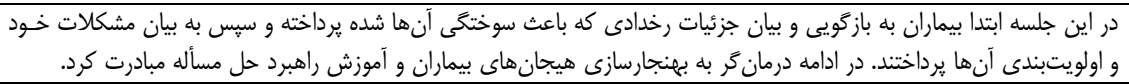 & 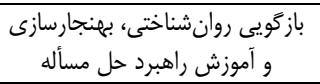 & دوم دوم \\
\hline 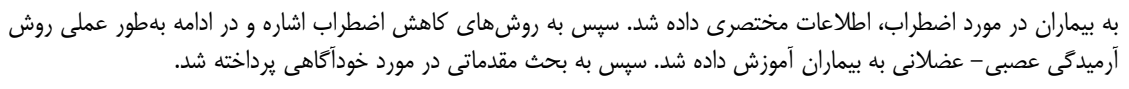 & 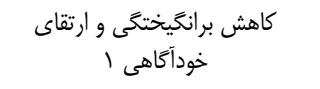 & سوم س \\
\hline 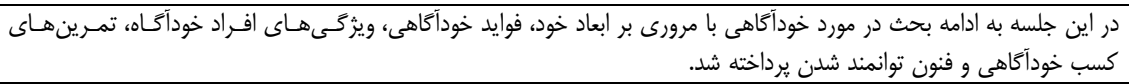 & 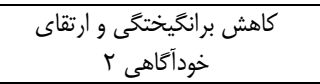 & جيهارم \\
\hline 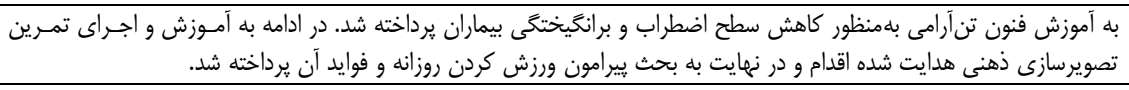 & أموزش آرميدگى و تصويرسازى هدايت شده & ينجم \\
\hline 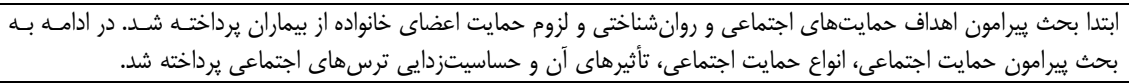 & ف & مشهم \\
\hline 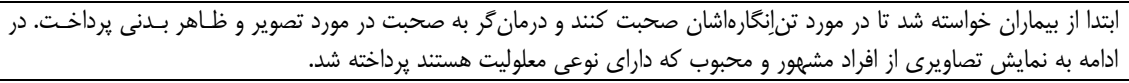 & 1 & هفتم \\
\hline 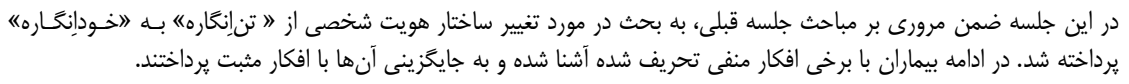 & r & هشتم \\
\hline 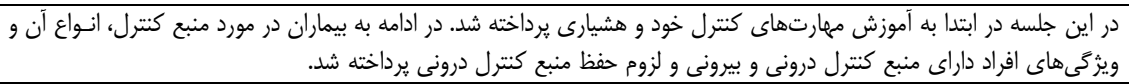 & آموزش مهارتهاى كنترل خود و & نهקم \\
\hline در اين جلسه به آموزش مهارتهاى مقابلهاى بينفردى و آموزش مهارتهاى ارتباط مؤثر با مشاركت آزمودنى ها يرداخته شد. & 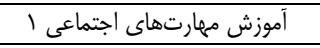 & دهم \\
\hline 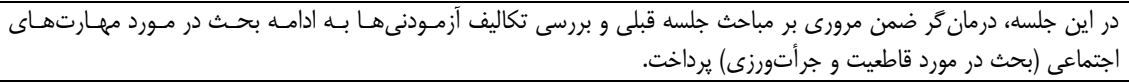 & مورس مهيرس & يازدهم \\
\hline 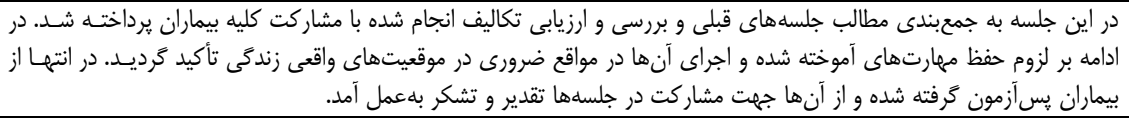 & جمعبندى و اج & ازدهم \\
\hline
\end{tabular}


جدول ץ- ويزَّى هاى جمعيتشناختى تَروهاى مورد بررسى

\begin{tabular}{|c|c|c|c|c|c|}
\hline \multicolumn{2}{|c|}{ شاهد } & \multicolumn{2}{|c|}{ آزمايش } & \multirow{2}{*}{\multicolumn{2}{|c|}{ ويزَى جمعيتشناختى }} \\
\hline درصد & فراوانى & درصد & فراوانى & & \\
\hline $99 / \mathrm{V}$ & 1. & $\mu \cdot / \Lambda$ & f & مجرد & \multirow{3}{*}{ وضعيت تأهل } \\
\hline ك & $\Delta$ & $\Delta r / \Lambda$ & v & متأهل & \\
\hline - & $\cdot$ & $10 / 4$ & $r$ & مطلقه & \\
\hline$r e / V$ & f & $\mathrm{HN} / \Delta$ & $\Delta$ & درجه r & \multirow{2}{*}{ درجه سوختخى } \\
\hline$V \Psi / r$ & 11 & $9 / / 0$ & $\Lambda$ & درجه r & \\
\hline $9 / V$ & 1 & $V / V$ & 1 & الكتريكى & \multirow{5}{*}{ عامل سوختگى } \\
\hline$\Delta \Gamma / \Gamma$ & 1 & 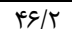 & 9 & شعله & \\
\hline$g / V$ & 1 & - & . & جسم داغ & \\
\hline$\mu r / r$ & $\Delta$ & $\mathrm{rN} / \mathrm{\Delta}$ & $\Delta$ & مايعات & \\
\hline$\cdot$ & . & $V / V$ & 1 & عامل شيميايى & \\
\hline$V \pi / \mu$ & 11 & $\Delta r / \lambda F$ & v & كمتر از • السال & \multirow{3}{*}{ مدت زمان سوختخى } \\
\hline r. & $r$ & $r \mu / \cdot V$ & $r$ & Iا تا •r سال & \\
\hline $9 / 9 V$ & 1 & $r \pi / \cdot V$ & $r$ & آr تا •r سال & \\
\hline
\end{tabular}

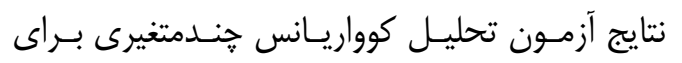
متغير راهبردهاى تنظيم هيجان نشان مىدهد كـهـ نتسايج

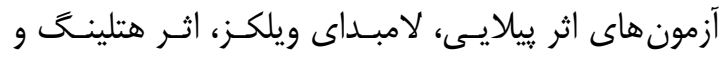

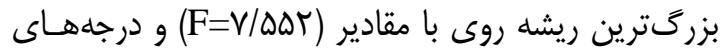

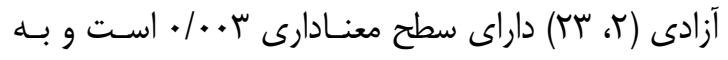

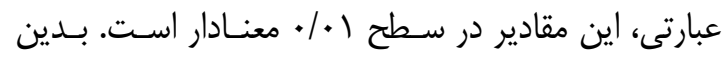

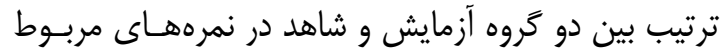

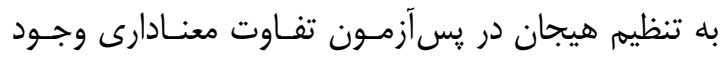

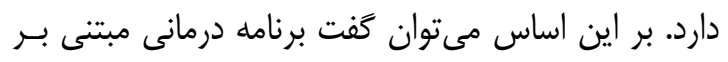

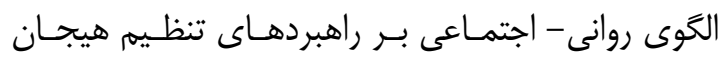
مؤثر بـوده است.

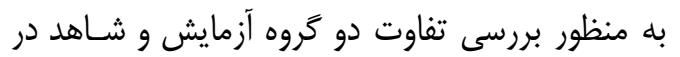

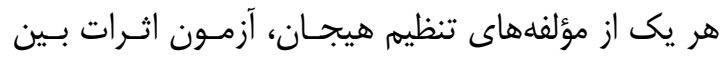

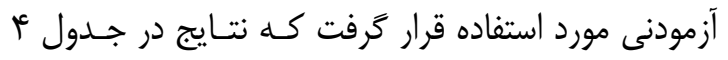

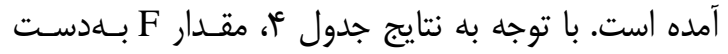

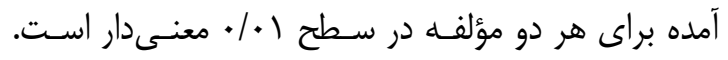

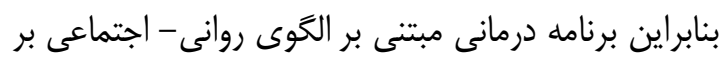

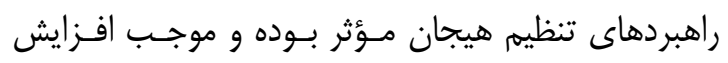

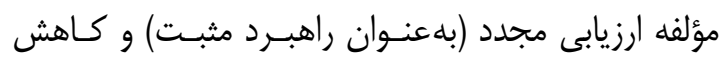

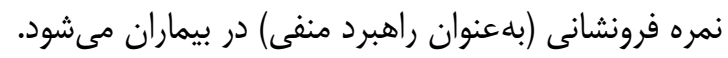

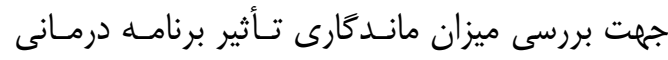

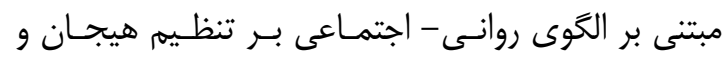

نتايج جدول ب نشان مىدهد ميانگين راهبرد هيجـانى

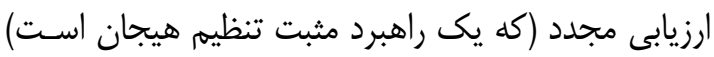

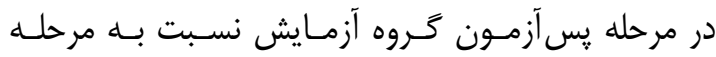
ييش آزمون افزايش يافته است كه اين افزايش در مر مرحلـه

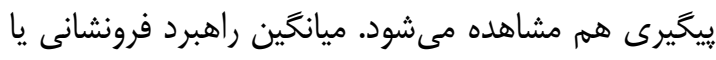

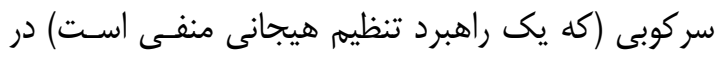

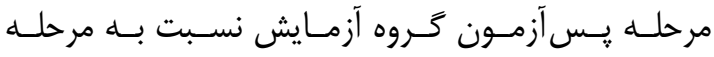

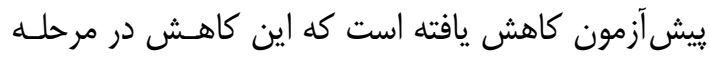
ييخيرى هم ماندكار بوده است.

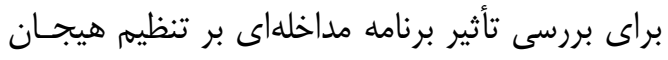
از روش تحليل كوواريانس تجندمتغيره استفاده شد. سـطح بـاني

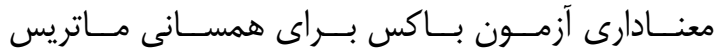

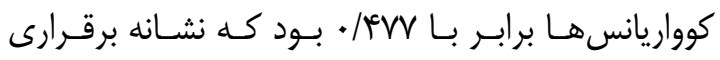

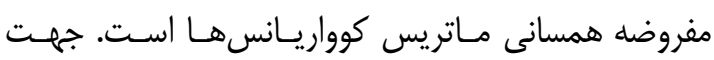

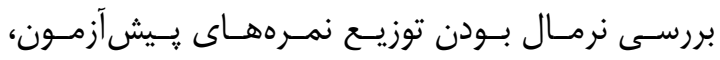

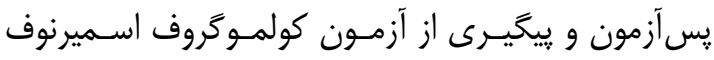

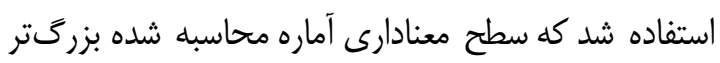

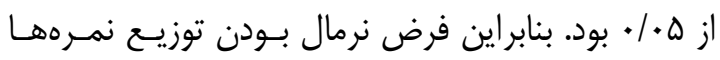
يذيرفته مى شود. براى بررسى همخنى واريانس متغيرهـاى

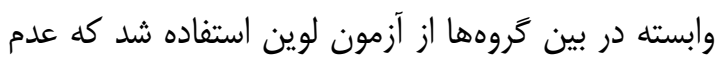

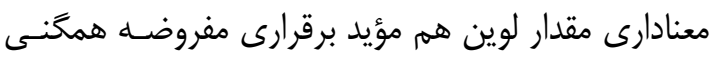
واريانس ها است. - معاري مقارين 
است. در نتيجه، برنامه درمانى مبتنى بـر الخــوى روانـىـ

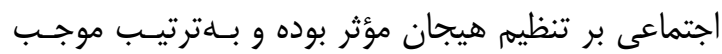

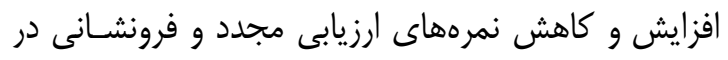
مرحله يِيگيرى مىشود.

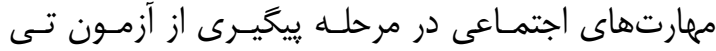

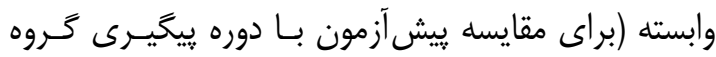

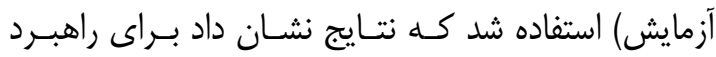

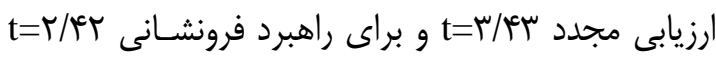

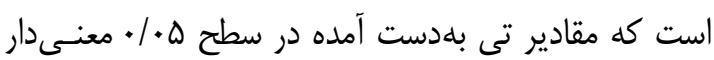

جدول ب- ميانكَين و انحراف استاندارد نمرههاى تنظيم هيجان به تفكيك تروه آزمايش و شاهد

\begin{tabular}{|c|c|c|c|c|c|c|c|}
\hline \multicolumn{2}{|c|}{ ييخيرى } & \multicolumn{2}{|c|}{ يس آزمون } & \multicolumn{2}{|c|}{ بيش آزمون } & \multirow[b]{2}{*}{ متغير } & \multirow[b]{2}{*}{ كروه } \\
\hline انحراف استاندارد & ميانگين & انحراف استاندارد & ميانكين & انحراف استاندارد & ميانكين & & \\
\hline & & $\Delta / \Lambda F$ & TV/AS & $\Delta / 1$. & $r \varepsilon / q \mu$ & ارزيابى مجدد & \multirow{3}{*}{ شاهد } \\
\hline & & $\Delta / I V$ & $1 \pi / 4$ & s/WV & $\mid r / I \pi$ & فرونشانى & \\
\hline & & $N / q^{\mu}$ & FI/Te & Q/QT & $r N \cdot 9$ & تنظيم هيجان & \\
\hline$\Delta / 1$. & $r N / r \Lambda$ & $\Delta / 1$. & $r / / v g$ & $V / \pi r$ & $r \mu / r$. & ارزيابى مجدد & \multirow{3}{*}{ آزمايش } \\
\hline$r / r v$ & $11 / r \wedge$ & $r / T \Lambda$ & 1./Ar & $4 / 19$ & $1 r / 94$ & فرونشانى & \\
\hline$\Delta / A F$ & $\mathrm{rq} / \mathrm{vg}$ & $s / r^{\prime}$ & $F T / 91$ & $8 / 91$ & $r V / \Gamma \mu$ & تنظيم هيجان & \\
\hline
\end{tabular}

جدول ع- آزمون اثرات بين آزمودنى براى مقايسه مؤلفههاى تنظيم هيجان تروه آزمايش و شاهد در يسآزمون

\begin{tabular}{|c|c|c|c|c|c|c|c|}
\hline اندازه اثر & سطح معنىدارى & $\mathrm{F}$ & ميانكين مجذورات & درجه آزادى & مجموع مجذورات & منبع & متغير \\
\hline \multirow[t]{2}{*}{.$/ M A T$} & $* . / . r$ & $\Delta / \Gamma \Delta$ & $1 \% \Delta / 90$ & 1 & $1 \% \Delta / q \Delta$ & بينگروهى & \multirow{2}{*}{ ارزيدابى } \\
\hline & & & $r \Delta / r q$ & $r \varepsilon$ & $9.9 / 49$ & درونَّروهى & \\
\hline \multirow[t]{2}{*}{. /TAF } & $* .1 . .9$ & $N / I V$ & $81 / 91$ & 1 & $91 / 91$ & بين كروهى & \multirow{2}{*}{ فرونشانى } \\
\hline & & & $V / \Delta V$ & rF & $|1| / V V$ & درون گروهى & \\
\hline
\end{tabular}

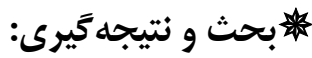

تعديل مى كنند. اين نتايج نشان مسىدهنــ اسـترس حـاد

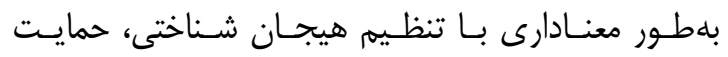

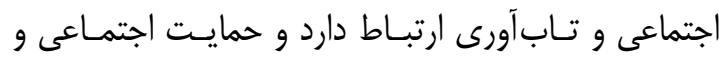

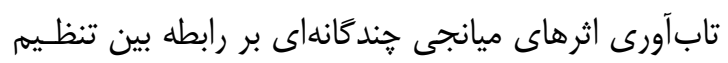

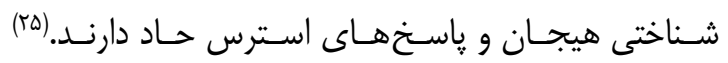

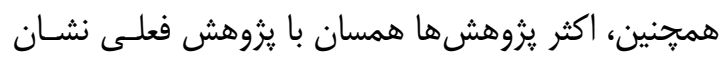
دادهاند، افرادى كه داراى مشكل در تنظيم هيجان شـامل

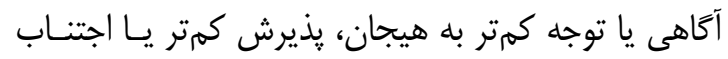

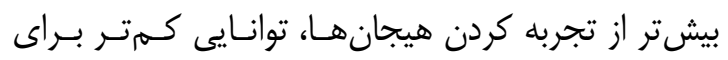

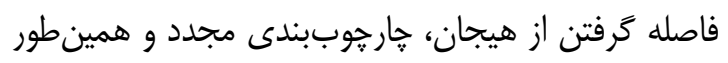

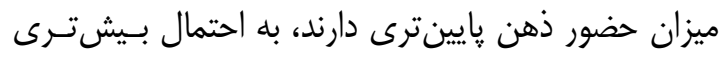

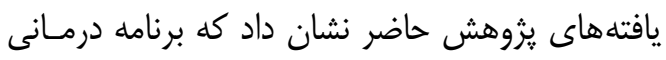
بر راهبردهاى تنظيم هيجان مؤثر بوده و موجـب افـزايش

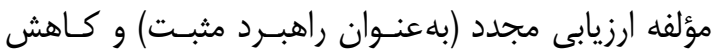

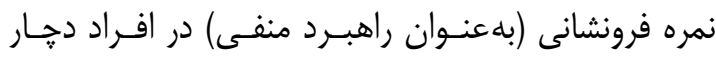

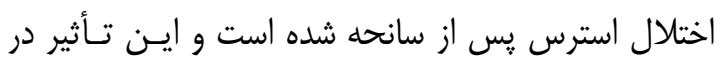

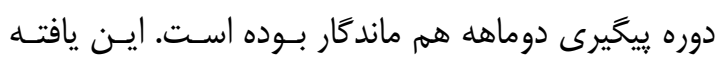

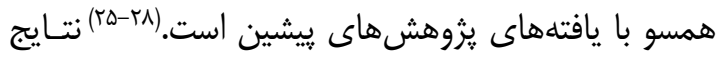

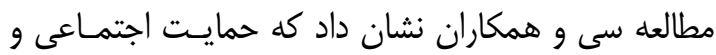

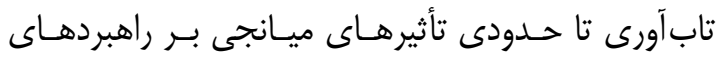

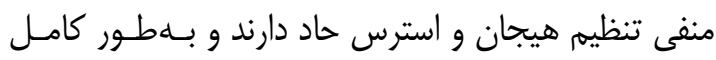
روابط راهبردهاى مثبت تنظيم هيجـان و اسـترس حـاد را 
زندگى با آسيب سوختخى نشان داد كه تجربه زندگى ايـن

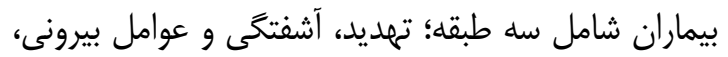

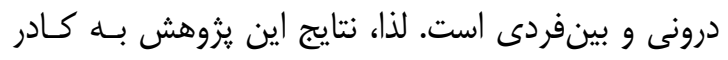

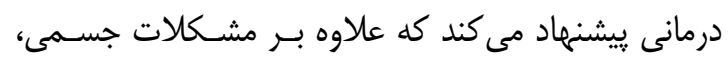

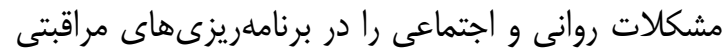

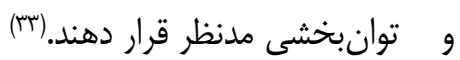

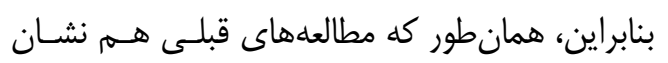

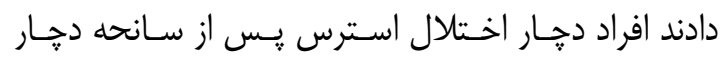

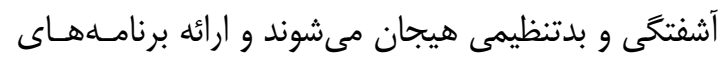

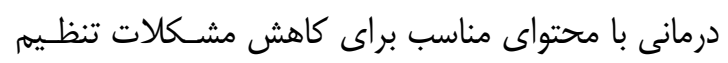

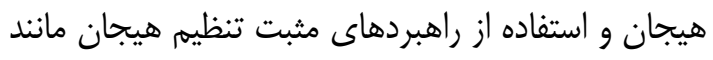

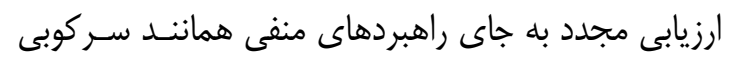

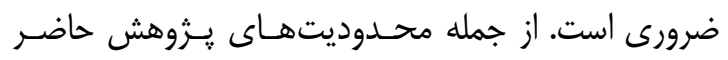

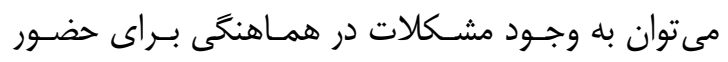

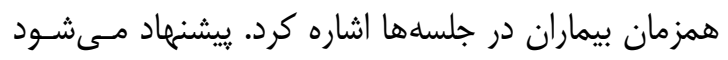

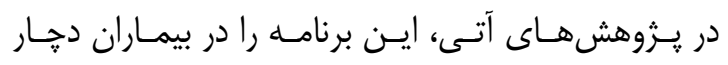

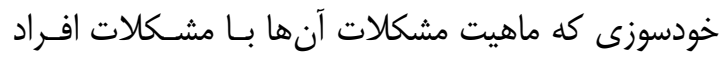

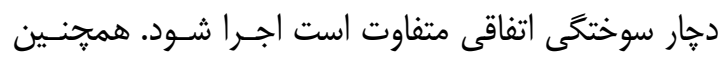

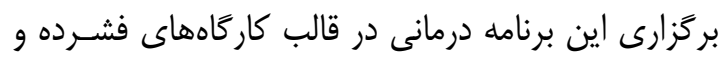
كوتاهمدت براى كليه بيماران سوختخى بلهويزه افراد دهـار اختلال استرس يس از سانحه يِيشنهاد مى شيود.

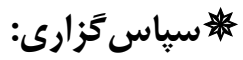

اين يزوهش بخشى از رسـاله دكتـراى آقـاى يوسـف

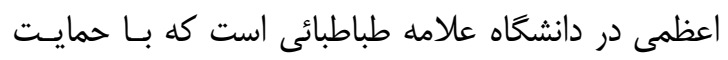

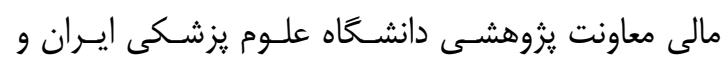

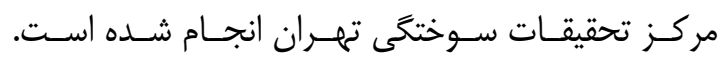

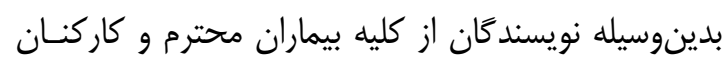

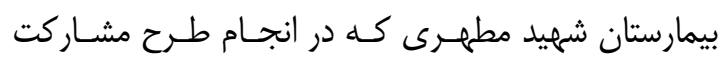
داشتند، سباس كزارى مى نمايند.

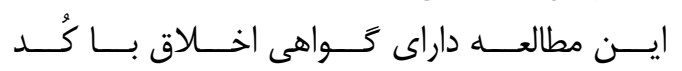

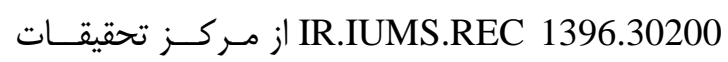

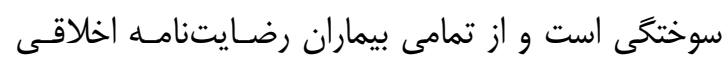
جهت شركت در يزوهش اخذ شده است.
در معرض آسيبشناسى روانى شامل اختلالهـاى مـرتبط با استرس در كوتاهمدت و در بلندمدت قرار دارند. بـهـطــور كلى در آسـيبشناسـى روانسى، روابـط معنسى دارى بــين

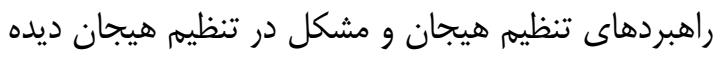

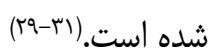

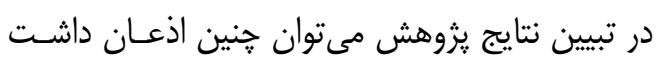

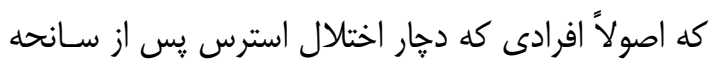

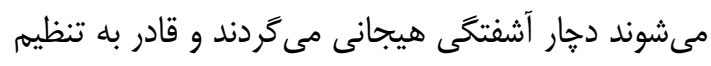

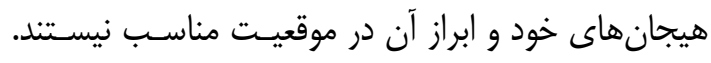

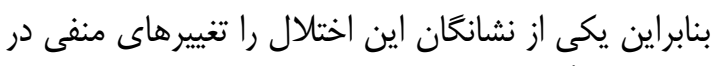

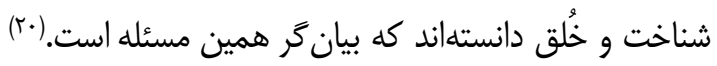
در مدل سلوجهى كلاركى و واتسون، عاطفهيذيرى منفى إنى

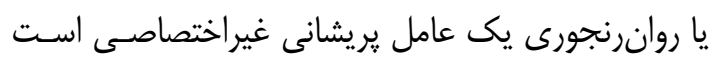

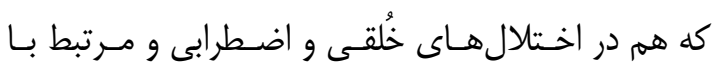

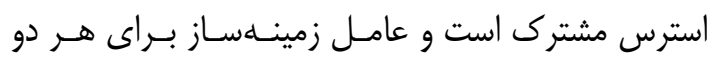

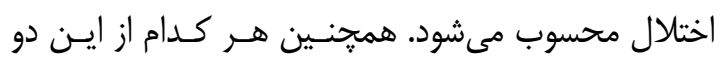

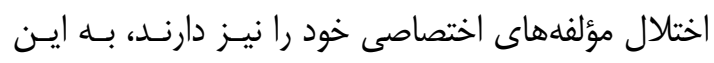

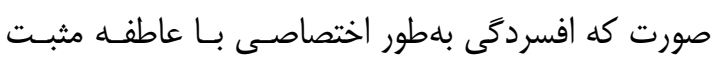

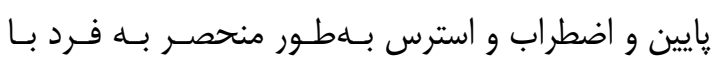
برانخيختخى خودكار رابطه دارد.

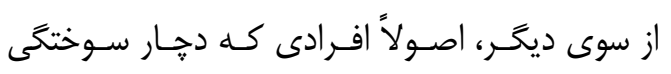

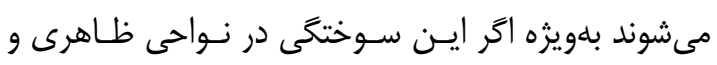

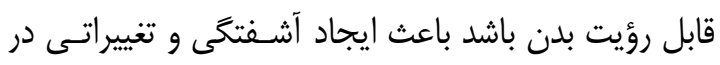

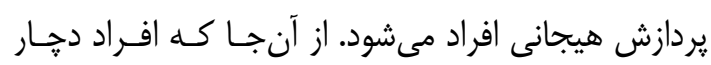

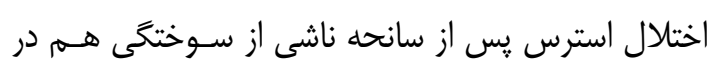

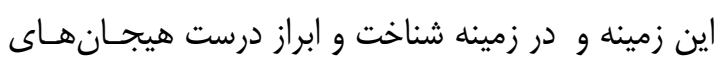

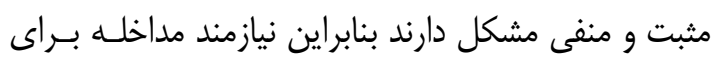

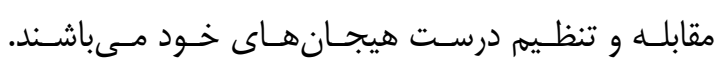

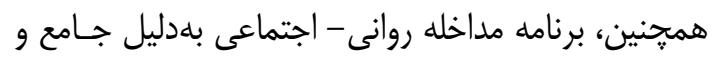

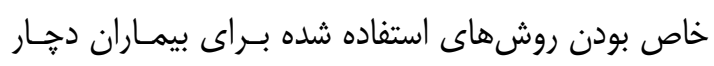

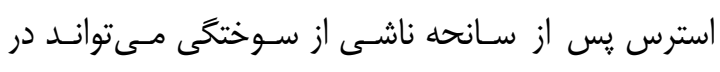

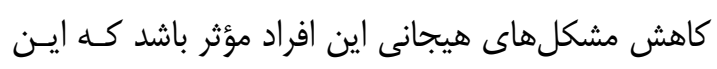

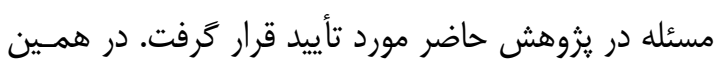

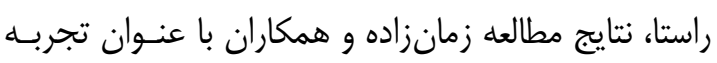


1. Alaghehbandan R, Azimi L, Rastegar Lari A. Nosocomial infections among burn patients in Teheran, Iran: a decade later. Ann Burns Fire Disasters 2012; 25(1): 3-7.

2. Kumar S, Ali W, Verma AK, Pandey A, Rathore S. Epidemiology and mortality of burns in the Lucknow Region, India-a 5 year study. Burns 2013; 39(8): 1599-605. doi: 10. 1016/j.burns.2013.04.008.

3. Aghakhani K, Aram S, Mehrpisheh S, Memarian A, Hoseini R, Ghorbani M. Evaluating the role of gender in the etiology, demographic features and prognosis of burn patients admitted to Shahid Motahari hospital: a five-year retrospective study. Razi J Med Sci 2015; 21(127): 95-101. [In Persian] 4. Herndon DN. Total burn care. 2nd ed. London: WB Saunders; 2007; 110-1.

5. Van Loey NE, Van Son MJ. Psychopathology and psychological problems in patients with burn scars: epidemiology and management. Am J Clin Dermatol 2003; 4(4): 245-72.

6. Rahbarian M, Tarkhan M, Jalali M. The effectiveness of cognitive-behavioral group therapy on self-concept and body image in burnt women. J Qazvin Univ Med Sci 2012; 15(4): 45-52. [In Persian]

7. Park SY, Choi KA, Jang YC, Oh SJ. The risk factors of psychosocial problems for burn patients. Burns 2008; 34(1): 24-31. doi: 10. 1016/j.burns.2007.03.012.

8. Wisely JA, Tarrier N. A survey of the need for psychological input in a follow-up service for adult burn-injured patients. Burns 2001; 27(8): 801-7. doi: 10.1016/S0305-4179(01) 00058-4.

9. Palmu R, Suominen K, Vuola J, Isometsä E. Mental disorders after burn injury: a prospective study. Burns 2011;37(4): 601-9. doi: 10.1016/j.burns.2010.06.007.

10. Seyed Tabaee R, Rahmatinejad $P$, Mohammadi D, Etemad A. The role of coping strategies and cognitive emotion regulation in well-being of patients with cancer. J Qazvin Univ Med Sci 2017; 21(2): 41-9. [In Persian]

11. Eysenck MW. A cognitive approach to trait anxiety. Eur J Pers 2000; 14(5): 463-76. doi: 10.1002/1099-0984(200009/10)14.

12. Frewen PA, Dozois DJ, Neufeld RJ, Lanius R. Disturbances of emotional awareness and expression in posttraumatic stress disorder: Meta-mood, emotion regulation, mindfulness, and interference of emotional expressiveness. Psychol TraumaUS 2012; 4(2): 152-61. doi: 10.1037/ a0023114.

13. Narimani M, Rajabi S. Comparison of the effect of Eye Movements and Reprocessing Desensitization (EMDR) with cognitivebehavioral therapy (CBT) in the treatment of stress disorders. Med Sci J Islamic Azad Univ Tehran Med Branch 2010; 19: 236-45. [In Persian]

14. Soleimani M, Ahmadi K, Mohammadi A. Virtual Reality Exposure Therapy in Anxiety Disorders and Posttraumatic Stress Disorder: A Systematic Review of Literature. J Res Behav Sci 2016; 14(1): 111-24. [In Persian] 15. Maredpour A, Najafi M. Effectiveness of eye movements and desensitization reprocessing treatment in women with post traumatic stress disorder due to civilian events. J Clin Psychol 2016; 6(23): 41-60. [In Persian]

16. Akbari Yeganeh Z, Dolatshahee B, Rezaee Dogaheh E. The effectiveness of neurofeedback training on reducing symptoms of war veterans with posttraumatic 
stress disorder. J Practice Clinical Psychology 2016; 4(1): 17-24.

17. Ahmadi Zadeh MJ, Ahmadi Kh, Anisi J. The survey of comparative effectiveness of skills problem solving education and prolonged exposure on treatment of post traumatic stress disorder. J Military Psychol (JMP) 2011; 1(4): 11-24. [In Persian]

18. Blakeney PE, Rosenberg L, Rosenberg M, Faber AW. Psychosocial care of persons with severe burns. Burns 2008; 34(4): 433-40. doi: 10.1016/j.burns.2007.08.008.

19. Biabangard I. Research methods in psychology and educational sciences. 7th ed. Tehran: Doran; 2012. 1(127). [In Persian]

20. Nasbum A. A practical guide to diagnostic interviews using DSM-5 criteria. Translated by: Rezaee F, Foroughi AA. 1st ed. Tehran: Arjmand; 2015. 95. [In Persian]

21. Weathers FW, Litz BT, Keane TM, Palmieri PA, Marx BP, Schnurr PP. The PTSD checklist for DSM-5 (PCL-5). Available at: www.ptsd.va.gov. Updated in: 2013.

22. Talebigi F. The effectiveness of acceptance and commitment-based therapy on reducing experience avoidance in veterans with impact stress disorder in Kerman. Master's Thesis of clinical psychology, Allameh Tabataba'i University; 2015. [In Persian]

23. Gross JJ, John OP. Individual differences in two emotion regulation processes: implications for affect, relationships, and well-being. J Pers Soc Psychol 2003; 85(2): 348-62.

24. Beyrami M, Akbari E, Ghasempour A, Azimi Z. An Investigation of Anxiety Sensitivity, Meta-Worry and Components of Emotion Regulation in Students with and without Social Anxiety. J Clin Psychol 2012;
2(8): 43-69. [In Persian]

25. Cai WP, Pan Y, Zhang SM, Wei C, Dong W, Deng GH. Relationship between cognitive emotion regulation, social support, resilience and acute stress responses in Chinese soldiers: exploring multiple mediation model. Psychiatry Res 2017; 256: 71-8. doi: 10. 1016/j.psychres.2017.06.018.

26. Pow AM. Coping with catastrophe: emotion regulation, adult attachment security, and mindfulness as predictors of posttraumatic stress among mental health disaster responders. Doctoral dissertation, University of North Carolina at Greensboro; 2014.

27. Stevens NR, Gerhart J, Goldsmith RE, Heath NM, Chesney SA, Hobfoll SE. Emotion regulation difficulties, low social support, and interpersonal violence mediate the link between childhood abuse and posttraumatic stress symptoms. Behav Ther 2013; 44(1): 152-61. doi: 10.1016/j.beth. 2012.09.003.

28. Mazlom M, Yaghoobi H, Mohammadkhani Sh. The relationship of metacognitive beliefs and emotion regulation difficulties with post traumatic stress disorder. J Behavioral Sciences 2014; 8(2): 105-13. [In Persian]

29. Hayes-Skelton SA, Calloway A, Roemer L, Orsillo SM. Decentering as a potential common mechanism across two therapies for generalized anxiety disorder. J Consult Clin Psychol 2015; 83(2): 395-404. doi: 10.1037/ a0038305.

30. Jazaieri H, Morrison AS, Goldin PR, Gross JJ. The role of emotion and emotion regulation in social anxiety disorder. Curr Psychiatry Rep 2015;17(1): 531. doi: 10. 1007/s11920-014-0531-3.

31. Taylor CT, Cross K, Amir N. Attentional 
control moderates the relationship between social anxiety symptoms and attentional disengagement from threatening information. J Behav Ther Exp Psychiatry 2016; 50: 6876. doi: 10.1016/j.jbtep.2015.05.008.

32. Aazami Y. The design and validation of psychosocial model-based treatment plan and its effectiveness in emotion regulation, social skills and improving the quality of life of people with PTSD resulting from burn. Doctoral dissertation, University of Allameh Tabataba'i; 2018. [In Persian]

33. Zamanzadeh V, Valizadeh L, Lotfi M, Salehi F. Life experience with burn injuries: A qualitative study. J Urmia Nurs Midwifery Fac 2015; 13(2): 124-35. [In Persian] 